\title{
(18P
}

\section{Tumor-node-metastasis staging and treatment patterns of 73,167 patients with lung cancer in Brazil}

\author{
Guilherme Jorge Costa1,2(1) , Maria Júlia Gonçalves de Mello³ \\ Anke Bergmann ${ }^{4}(\mathbb{D})$, Carlos Gil Ferreira ${ }^{5} \mathbb{D}$, Luiz Claudio Santos Thuler ${ }^{4,6} \mathbb{C}_{\mathbb{D}}$
}

1. Departamento de Ensino e Pesquisa, Hospital de Câncer de Pernambuco, Recife (PE) Brasil.

2. Departamento de Oncologia, Instituto de Medicina Integral Professor Fernando Figueira, Recife (PE) Brasil.

3. Departamento de Pesquisa Clínica, Instituto de Medicina Integral Professor Fernando Figueira, Recife (PE) Brasil.

4. Instituto Nacional de Câncer José Alencar Gomes da Silva, Divisão de Pesquisa Clínica e Programa de Pós-Graduação em Oncologia, Rio de Janeiro (RJ) Brasil.

5. Instituto Oncoclíncas, Rio de Janeiro (RJ) Brasil.

6. Universidade Federal do Estado do Rio de Janeiro, Rio de Janeiro (RJ) Brasil.

Submitted: 11 September 2018. Accepted: 22 April 2019

Study carried out in the Departamento de Ensino e Pesquisa, Hospital de Câncer de Pernambuco, Recife (PE) Brasil.

\begin{abstract}
Objective: To characterize the clinical and histological profile, as well as treatment patterns, of patients with early-stage, locally advanced (LA), or advanced/metastatic (AM) lung cancer, diagnosed between 2000 and 2014, in Brazil. Methods: This was an analytical cross-sectional epidemiological study employing data obtained for the 2000 2014 period from the hospital cancer registries of two institutions in Brazil: the José Alencar Gomes da Silva National Cancer Institute, in the city of Rio de Janeiro; and the São Paulo Cancer Center Foundation, in the city of São Paulo. Results: We reviewed the data related to 73,167 patients with lung cancer. The proportions of patients with early-stage, LA, and AM lung cancer were $13.3 \%, 33.2 \%$, and $53.4 \%$, respectively. The patients with early-stage lung cancer were older and were most likely to receive a histological diagnosis of adenocarcinoma; the proportion of patients with early-stage lung cancer remained stable throughout the study period. In those with LA lung cancer, squamous cell carcinoma predominated, and the proportion of patients with LA lung cancer decreased significantly over the period analyzed. Those with AM lung cancer were younger and were most likely to have adenocarcinoma; the proportion of patients with AM lung cancer increased significantly during the study period. Small cell carcinoma accounted for $9.2 \%$ of all cases. In our patient sample, the main treatment modality was chemotherapy. Conclusions: It is noteworthy that the frequency of AM lung cancer increased significantly during the study period, whereas that of LA lung cancer decreased significantly and that of early-stage lung cancer remained stable. Cancer treatment patterns, by stage, were in accordance with international guidelines.

Keywords: Lung neoplasms/epidemiology; Lung neoplasms/therapy; Neoplasm staging; Brazil.
\end{abstract}

\section{INTRODUCTION}

Lung cancer (LC) is the most common cancer and the leading cause of cancer death worldwide. In 2012, there were over 1.8 million new cases and 1.6 million deaths worldwide. ${ }^{(1)}$ For 2018, the Instituto Nacional de Câncer José Alencar Gomes da Silva (INCA, José Alencar Gomes da Silva National Cancer Institute) in Brazil estimates the occurrence of 31.270 new cases of trachea, bronchus, and LC: 18,740 in men and 12,530 in women. LC is the second most common cancer type among men and the fourth among women. ${ }^{(2)}$

The cancer staging system known as tumor-nodemetastasis (TNM) determines the extent of disease by assessing the size of the primary tumor $(T)$ and identifying whether there is any lymph node involvement $(\mathrm{N})$ and local or distant metastasis (M). Cancers are usually classified as early-stage disease (stage I and II), locally advanced disease (stage III), and advanced/metastatic disease (stage IV). Staging is an important step in the diagnostic process, being aimed at standardizing the main treatment modalities for each stage, as well as at estimating prognosis and comparing the results of various therapies and therapy combinations and/or various institutions. ${ }^{(3,4)}$

The high mortality of LC and its low 5-year survival rate are attributable to the high prevalence of locally advanced and advanced/metastatic disease at diagnosis, observed in $70 \%$ to $95 \%$ of cases. . $^{(5,6)}$ Clinically advanced/ metastatic LC has recently been identified in $54.9 \%$ to $57.4 \%$ of cases at diagnosis and is on the rise in Brazil. ${ }^{(7,8)}$ However, the other stages were not adequately assessed in those studies. $(7,8)$

Knowledge of the distribution of the clinical stages of LC is essential to optimizing smoking cessation programs, as well as cancer screening, diagnosis, and treatment at the national level, whether in the public or private sector. ${ }^{(9-12)}$ Therefore, using data from hospital cancer registries, the present study aimed to characterize the clinical and histological profile, as well as treatment patterns, of patients with early-stage, locally advanced, or advanced/metastatic LC, diagnosed between 2000 and 2014, in Brazil. 


\section{METHODS}

This was an analytical cross-sectional epidemiological study employing data on adult patients with LC in Brazil, recorded between 2000 and 2014. Patient data were obtained from the records in the Registro Hospitalar de Câncer (RHC, Hospital Cancer Registry) Integration System of the INCA, located in the city of Rio de Janeiro, Brazil, and from the RHC of the São Paulo Cancer Center Foundation, located in the city of São Paulo, Brazil, which together involve 258 hospitals in 27 Brazilian states and the Federal District of Brasília.

The aforementioned systems were designed to store and consolidate data from all RHC in Brazil and can be consulted on the Internet. We included cases of malignant neoplasm of bronchus and lung, according to the International Statistical Classification of Diseases and Related Health Problems, 10th edition (ICD-10 code C34), ${ }^{(13)}$ with the following morphologies, according to the International Classification of Diseases for Oncology, 3rd edition ${ }^{(14)}$ : adenocarcinoma (codes 8140, $8144,8211,8230,8250,8251,8252,8253,8254$, $8255,8260,8265,8256,8257,8310,8323,8333$, 8480,8481 , and 8551); squamous cell carcinoma (codes 8070, 8071, 8072, 8074, and 8083), small cell carcinoma (codes 8041 and 8045); and non-small cell carcinoma or undifferentiated carcinoma (code 8012). We excluded cases of patients who were under 18 years of age, had in situ carcinoma, or had lung tumors with other morphologies.

The 5 th edition of the TNM classification was used in the 2000-2005 period; the 6th edition ${ }^{(13)}$ was used in the 2006-2010 period; and the 7th edition ${ }^{(15)}$ was used in the 2011-2014 period. Patients were categorized into three groups: early-stage group (ESG), patients with early-stage (stage I and II) LC; locally advanced group (LAG), patients with locally advanced (stage III) disease; and advanced/metastatic group (AMG), patients with advanced/metastatic (stage IV) disease. The following variables were categorized and analyzed: age group (18-49, 50-69, or $\geq 70$ years); histological type $^{(16)}$ (adenocarcinoma, squamous cell carcinoma, undifferentiated carcinoma, or small cell carcinoma); smoking (never smoker or former smoker/smoker); race (White or Black/Brown); time from diagnosis to treatment initiation ( $<60$ days or $\geq 60$ days); death at the end of the first treatment (yes or no); response to the first treatment (response [complete or partial response/stable disease] or no response [disease progression, recurrence, or death]); and first line of treatment (surgery alone, surgery + radiotherapy, surgery + chemotherapy, surgery + chemotherapy + radiotherapy, chemotherapy + radiotherapy, surgery at some point, radiotherapy at some point, and chemotherapy at some point).

\section{Statistical analysis}

Data analysis was performed with the IBM SPSS Statistics software package, version 21.0 (IBM Corporation, Armonk, NY, USA). Measures of central tendency and dispersion were calculated for continuous variables, and frequency distribution was calculated for categorical variables. We used the chi-square test to compare the frequencies of categorical variables, considering valid data. To determine annual variation, we calculated the coefficient of determination. Differences were considered significant if $\mathrm{p}<0.05$.

The present study was approved by the Research Ethics Committee of the Professor Fernando Figueira Institute of Integrative Medicine (Protocol no. 3681 of 2013).

\section{RESULTS}

According to the RHC data, there were 103,658 cases of LC during the study period. A total of 30,491 records $(29.4 \%)$ were excluded from the analysis because of missing data on TNM stage. Therefore, the study included 73,167 cases of patients diagnosed with LC between 2000 and 2014 in Brazil.

The main sociodemographic, clinical, and disease course characteristics of the cases, by stage, are shown in Table 1 . There were 9,644 patients (13.2\%) in the ESG; $24,511(33.5 \%)$ in the LAG; and 39,012 $(53.3 \%)$ in the AMG.

An analysis of the distribution of all early-stage, locally advanced, and advanced/metastatic LC cases between 2000 and 2014, by year of diagnosis, showed that relative frequency remained stable, trending slightly downward, in the ESG; decreased significantly in the LAG; and increased progressively and significantly in the AMG.

The mean age of the entire study sample was 63.5 \pm 10.7 years, and $18 \%$ of the patients were never smokers (Table 1 ). There was a progressive increase in mean age at diagnosis in the three groups studied (Figure 1).

Patients with non-small cell carcinoma accounted for $90.8 \%$ of the sample, and this proportion trended slightly upward over the years evaluated. Patients with small cell carcinoma accounted for $9.2 \%$ of the sample, and their temporal distribution was opposite, trending slightly downward over the same period. Adenocarcinoma was the most common histological type (in $39.8 \%$ ), followed by squamous cell carcinoma (in $29.0 \%$ ) and undifferentiated carcinoma (in $22.1 \%$; Table 1).

Chemotherapy was the most common treatment modality, in $59.4 \%$ of the patients, followed by radiotherapy (in $41.3 \%$ ) and surgery (in 14.8\%). No cancer treatment was administered to 10,766 patients (14.7\%; Table 1).

In the ESG, the mean age was $64.8 \pm 10.8$ years, higher than that in the two other groups. Adenocarcinoma was the main histological type (in $42.3 \%$ ), and the proportion of patients in whom the time from diagnosis to treatment initiation was $\geq 60$ days $(14.9 \%)$ was higher than that in the two other groups. The main treatment modality was surgery alone or in combination with other modalities (in $43.1 \%$ ), 

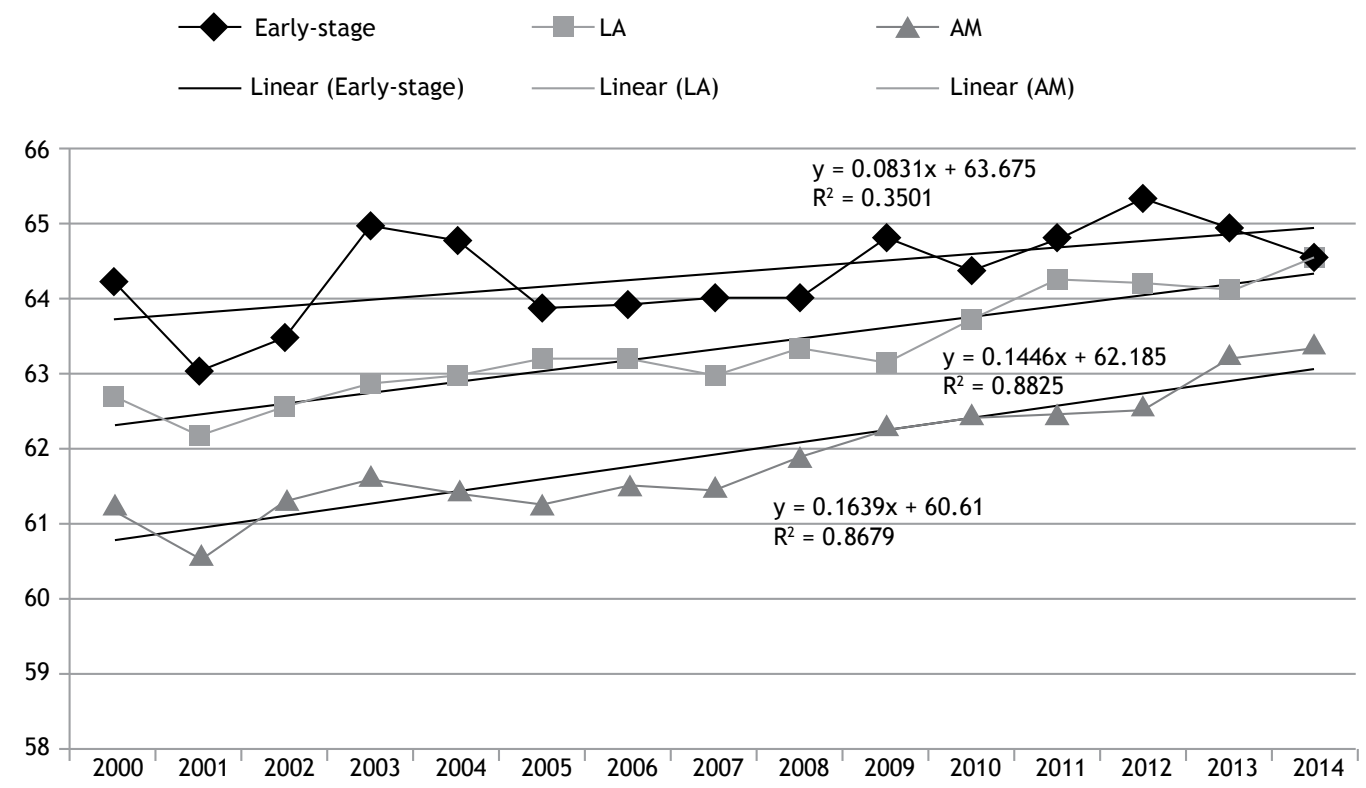

Figure 1. Distribution of all early-stage, locally advanced (LA), and advanced/metastatic (AM) lung cancer cases, by mean age and year of diagnosis, Brazil.

followed by chemotherapy (in 40.5\%) and radiotherapy (in $32.2 \%$ ). No treatment was administered in $10.8 \%$ of the cases. Death at the end of the first treatment occurred in $24.3 \%$ of the cases in the ESG. As shown by temporal analysis, the number of patients in the ESG remained stable throughout the period analyzed (Figure 2).

The LAG had the highest proportion of smokers $(40.9 \%)$, and squamous cell carcinoma was the most common histological type at diagnosis; the proportion of patients with locally advanced LC decreased significantly during the study period (Figure 2 ). The main treatment modality was chemotherapy alone or in combination with other modalities (in 66.6\%), followed by radiotherapy (in $48.7 \%$ ) and surgery (in $16.8 \%)$. No treatment was administered in $11.8 \%$ of the cases (Table 1 ).

In the AMG, the mean age was lower than that in the two other groups. As shown by temporal analysis, advanced/metastatic LC was the most prevalent stage of LC in our patient sample, and the proportion of patients with advanced/metastatic LC increased significantly over the period analyzed. Adenocarcinoma was the predominant histological type (in $45.3 \%$ ), and the proportion of patients in whom the time from diagnosis to cancer treatment initiation was $\geq 60$ days was lower than that in the two other groups. The main treatment modality was chemotherapy (in $59.7 \%$ ), followed by radiotherapy (in $38.9 \%$ ) and surgery (in $12.6 \%$ ). No treatment was administered to $17.4 \%$ of the patients. The AMG had the highest proportion of deaths at the end of the first treatment (47.4\%).

The proportion of patients with adenocarcinoma trended upward in the ESG and the AMG, whereas it decreased significantly in the LAG (Figure 3A). The proportion of patients with squamous cell carcinoma was highest in the LAG; however, because this proportion decreased in the LAG and increased in the AMG, the latter group surpassed the former in the proportion of such patients as of 2011 (Figure 3B). The proportion of patients with small cell carcinoma trended downward in the ESG and the LAG during the study period (Figure 3C).

\section{DISCUSSION}

The present study, which evaluated 73,167 patients with LC, diagnosed between 2000 and 2014, in Brazil, showed that the prevalence of locally advanced LC decreased significantly during the study period, whereas that of advanced/metastatic LC increased significantly and that of early-stage LC remained stable. It also showed that surgery was the main treatment modality in the ESG, whereas chemotherapy was the main treatment modality in the LAG and the AMG.

Small cell carcinoma was identified in $9.2 \%$ of all patients in the present study, a frequency similar to those reported in the literature $(10-15 \%)$ for the world population, ${ }^{(17)}$ and the frequency of small cell carcinoma trended slightly downward during the study period. This decline in prevalence could be explained by the high correlation between small cell carcinoma and smoking, the prevalence of which is decreasing in Brazil; however, the behavior of this histological subtype was much more stable than that of squamous cell carcinoma, also a subtype frequently related to smoking, ${ }^{(8)}$ in terms of the magnitude of the decrease in prevalence. Adenocarcinoma already is the most prevalent histological subtype in Brazil(8) and many other countries, is less correlated with smoking, 
Table 1. Characteristics of the 73,167 patients with lung cancer in the study. Brazil, 2000-2014.

\begin{tabular}{|c|c|c|c|c|}
\hline Characteristic & $\begin{array}{c}\text { ESG } \\
\text { Stage I and II } \\
n(\%)\end{array}$ & $\begin{array}{c}\text { LAG } \\
\text { Stage III } \\
\text { n (\%) }\end{array}$ & $\begin{array}{c}\text { AMG } \\
\text { Stage IV } \\
\text { n (\%) }\end{array}$ & p* \\
\hline Number of patients & $9,644(13.3)$ & $24,511(33.2)$ & $39,012(53.4)$ & \\
\hline Age, years (mean $\pm S D$ ) & $64.8 \pm 10.8$ & $63.4 \pm 10.5$ & $62.2 \pm 11.0$ & $<0.001$ \\
\hline Age group, years & & & & $<0.001$ \\
\hline - $18-49$ & $822(8.5)$ & 2,417 (9.9) & $4,847(12.4)$ & \\
\hline - 50-69 & $5,412(56.1)$ & $14,759(60.2)$ & $23,652(60.6)$ & \\
\hline$\bullet \geq 70$ & $3,410(35.4)$ & 7,335 (29.9) & $10,513(26.9)$ & \\
\hline Gender & & & & $<0.001$ \\
\hline - Male & $5,988(62.1)$ & $16,541(67.5)$ & $24,367(62.5)$ & \\
\hline - Female & $3,656(37.9)$ & $7,970(32.5)$ & $14,645(37.5)$ & \\
\hline Race $^{a}$ & & & & $<0.001$ \\
\hline - White & $3,051(31.6)$ & $8.852(36.1)$ & $12,812(32.8)$ & \\
\hline - Black/Brown & $1,408(14.6)$ & $5,199(21.2)$ & $7,845(20.1)$ & \\
\hline - No data & $4.735(49.1)$ & $10,460(42.7)$ & $20,657(47.1)$ & \\
\hline Smoking ${ }^{\mathrm{a}}$ & & & & $<0.001$ \\
\hline - No smoker & $587(6.1)$ & $1,715(7.0)$ & $3,342(8.5)$ & \\
\hline - Smoker/former smoker & $3,006(31.1)$ & $10,030(40.9)$ & $13,109(33.6)$ & \\
\hline - No data & $6,266(62.7)$ & $13,026(52.1)$ & $23,264(57.8)$ & \\
\hline Histology & & & & $<0.001$ \\
\hline - Adenocarcinoma & $4,079(42.3)$ & $7,373(30.1)$ & $17,658(45.3)$ & \\
\hline - Squamous cell carcinoma & $3,413(35.4)$ & $9,701(39.6)$ & $8,095(20.8)$ & \\
\hline - Undifferentiated carcinoma & $1,629(16.9)$ & $5,323(21.7)$ & $9,193(23.6)$ & \\
\hline - Small cell carcinoma & $523(5.4)$ & $2,114(8.6)$ & $4,066(10.4)$ & \\
\hline Time from diagnosis to treatment initiation & & & & $<0.001$ \\
\hline$\bullet<60$ days & $3,231(33.5)$ & $11,613(47.4)$ & $18,299(46.9)$ & \\
\hline - $\geq 60$ days & $1,440(14.9)$ & $3,221(13.1)$ & $4,510(11.6)$ & \\
\hline No data & $5,185(51.6)$ & $9,851(39.5)$ & $16,649(41.5)$ & \\
\hline First line of treatment & & & & $<0.001$ \\
\hline - No treatment & $1,043(10.8)$ & 2,906 (11.9) & $6,817(17.5)$ & \\
\hline - Surgery alone & $943(9.7)$ & $384(1.6)$ & $597(1.5)$ & \\
\hline - Surgery + radiotherapy & $590(6.1)$ & $1,076(4.4)$ & $1,452(3.7)$ & \\
\hline - Surgery + chemotherapy & $1,418(14.7)$ & $1,835(7.5)$ & $2,233(5.7)$ & \\
\hline - Surgery + chemotherapy + radiotherapy & $355(3.7)$ & $811(3.3)$ & $1,002(2.6)$ & \\
\hline - Chemotherapy + radiotherapy & $1,349(14.0)$ & 7,762 (31.7) & $8,488(21.7)$ & \\
\hline - Surgery at some point & $4,153(43.1)$ & $2,809(11.5)$ & $3,832(9.8)$ & \\
\hline - Chemotherapy at some point & $3,940(40.5)$ & $16,303(66.6)$ & $23,205(59.7)$ & \\
\hline - Radiotherapy at some point & $3,103(32.2)$ & $11,958(48.8)$ & $15,213(39.0)$ & \\
\hline Response to the first treatment ${ }^{a}$ & & & & $<0.001$ \\
\hline - Response $\mathrm{e}^{\mathrm{b}}$ & $1,751(18.1)$ & $3,629(14.8)$ & $3,082(7.9)$ & \\
\hline - No response ${ }^{\mathrm{b}}$ & $1,115(11.5)$ & $5,853(23.9)$ & $10,431(26.7)$ & \\
\hline - No data & $6,778(70.3)$ & $15,029(61.3)$ & $25,499(65.4)$ & \\
\hline Early death ${ }^{c}$ & & & & $<0.001$ \\
\hline - Yes & $2,348(24.3)$ & $9,149(37.3)$ & $18,446(47.3)$ & \\
\hline
\end{tabular}

Source: Hospital Cancer Registry Integration System of the Instituto Nacional do Câncer (INCA, National Cancer Institute) and Hospital Cancer Registries of the Fundação Oncocentro de São Paulo (FOSP, São Paulo Cancer Center Foundation). ESG: early-stage group; LAG: locally advanced group; and AMG: advanced/metastatic group. aData not evaluated for the state of São Paulo $(n=34,181)$. Percentages based on valid data. ${ }^{b}$ Response: complete or partial response, stable disease; and No response: progression, recurrence, or death. 'Deaths at the end of the first treatment (INCA) or within 24 months after diagnosis (FOSP). *Chi-square test.

and trends toward a global increase in prevalence as compared with the other subtypes. ${ }^{(18-20)}$

In the present study, the proportional distribution of poor-prognosis stages is alarming but is similar to that found in the United States and the United Kingdom. Analyzing the mean proportions for each year during the study period (2000-2014), we found that early-stage LC, locally advanced LC, and advanced/metastatic LC 

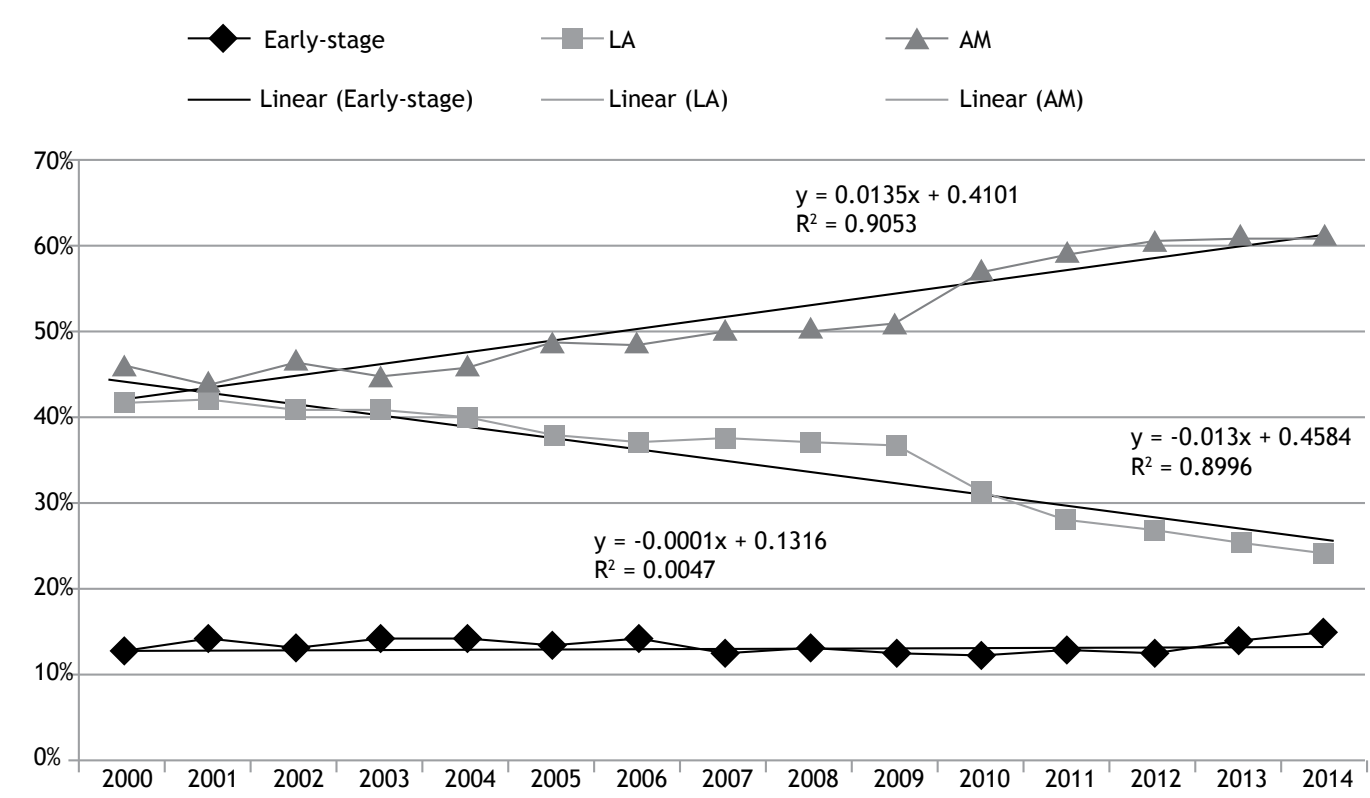

Figure 2. Distribution of all early-stage, locally advanced (LA), and advanced/metastatic (AM) lung cancer cases, by year of diagnosis, Brazil.

accounted for $13.3 \%, 33.2 \%$, and $53.4 \%$ of the cases, respectively. In the United States, the proportions of early-stage, locally advanced, and advanced/metastatic LC cases were $15.9 \%, 22.0 \%$, and $57.0 \%$, respectively, in the 2008-2014 period. (21) In the United Kingdom, $\mathrm{LC}$ is the second most common cancer type in men and women, patients are diagnosed at stages III and IV in $87 \%$ of cases, and approximately $35 \%$ of cases are diagnosed after an emergency department visit. ${ }^{(22)}$

Further revisions to the TNM staging system ${ }^{(11)}$ and histological classifications $^{(17)}$ and the implementation and greater availability of new technologies for the diagnosis of metastatic lesions, as well as the increase in the number of cancer treatment centers in recent years, are possibly the main factors related to the increased proportion of LC cases diagnosed at an advanced stage in Brazil. The Expand project, developed by the Brazilian National Ministry of Health in conjunction with the INCA, has created 24 new oncology centers

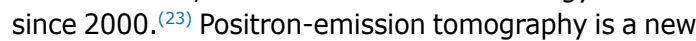
diagnostic technology that combines nuclear medicine and tomography, being more reliable and precise in staging LC when compared with tomography alone, as well as reducing futile treatments for patients and reducing costs to the health care system. ${ }^{(24)}$

The National Lung Screening Trial ${ }^{(25)}$ established that low-dose chest CT, repeated annually for 3 years when used for the screening of asymptomatic high-risk patients (age > 55 years, smokers with a smoking history $>30$ pack-years, and former smokers who have been abstinent for less than 15 years), increases survival in those with positive screening for LC, with a reduction of $20 \%$ in LC mortality and of almost $7 \%$ in all-cancer mortality. A study of LC screening, conducted in Brazil,(26) evaluated 790 high-risk patients and identified 312 (39.4\%) with nodules $>4 \mathrm{~mm}$; those 312 patients were followed by a multidisciplinary team. A total of 10 cases (3.2\%) of LC were found, suggesting that low-dose CT can and should be even used in a region with a high incidence of granulomatous diseases. In addition to identifying nodular lesions suspected of being LC, CT offers the benefit of incidental findings of other diseases, such as benign lung diseases (COPD, interstitial diseases, and bronchiectasis) and cardiovascular diseases (based on the degree of coronary artery calcification), at earlier stages; such findings are present in $24 \%$ to $64 \%$ of cases. ${ }^{(27)}$ However, LC screening is not yet available in Brazil via the Brazilian Unified Health Care System. Brazilian National Ministry of Health Directive no. 600 issued on June $26,2012{ }^{(28)}$ which approved diagnostic and treatment guidelines for LC, does not recommend the routine use of low-dose chest CT for this purpose.

Although Brazil is a worldwide reference in the fight against smoking, centers specializing in smoking cessation have yet to expand their actions. ${ }^{(29)}$ The prevention-related costs of smoking cessation programs are infinitely lower than the exorbitant costs of medical and hospital care for smoking-related diseases. In 2011, a study conducted in Brazil reported that smoking was responsible for 147,072 deaths, 2.69 million years of life lost, 157,126 cases of acute myocardial infarction, 75,663 cases of stroke, and 63,753 cases of cancer. The total cost to the health care system was 23.37 billion Brazilian reals. ${ }^{(30)}$ Combining screening programs with smoking cessation programs appears to be far more effective in reducing costs and mortality from LC and other causes. ${ }^{(25,31)}$

The training of primary and secondary health care professionals also needs to be optimized so that LC can be diagnosed as early as possible. Lista et al. ${ }^{(32)}$ retrospectively evaluated 372 patients with LC who were 
(A)

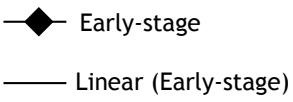

- LA
L Linear (LA) $\rightarrow \mathrm{AM}$

- Linear (AM)

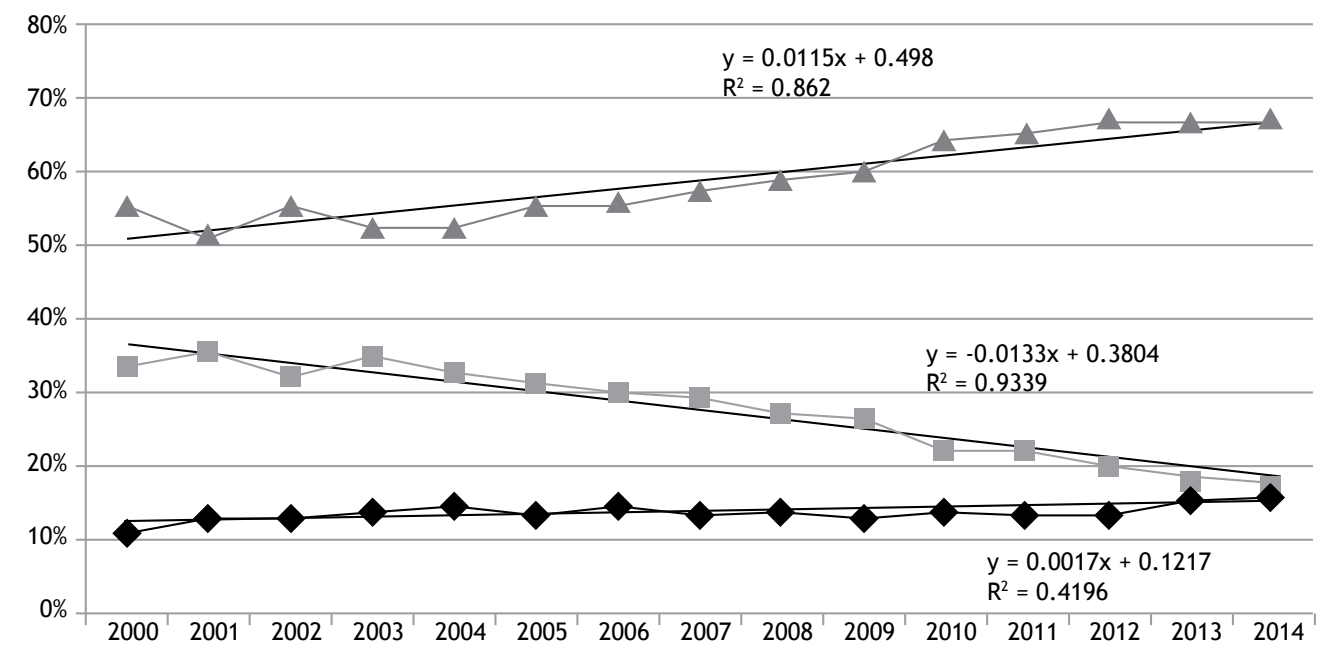

(B)

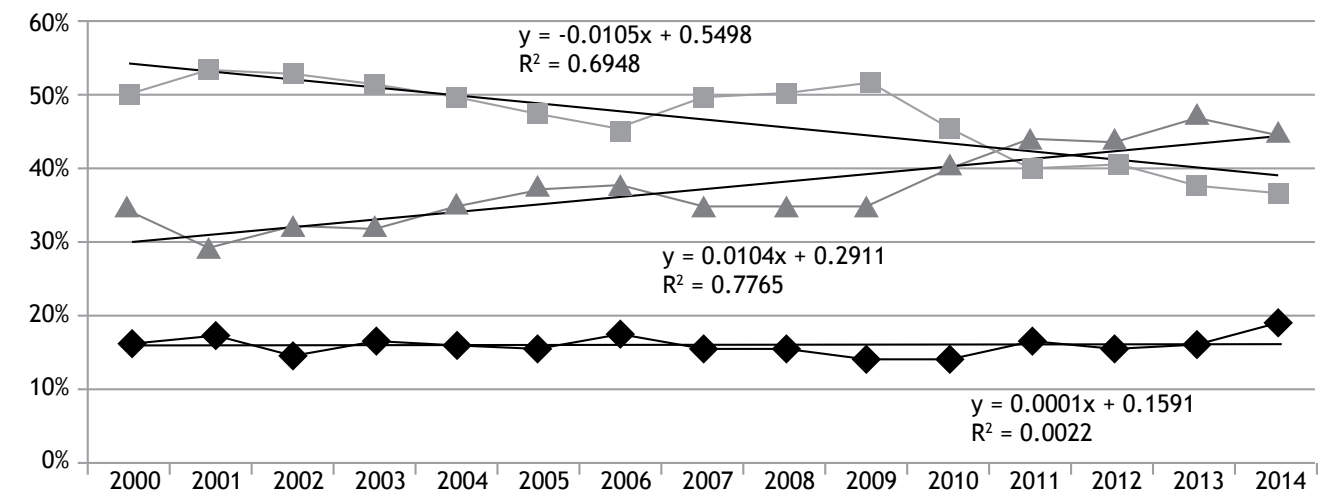

(C)

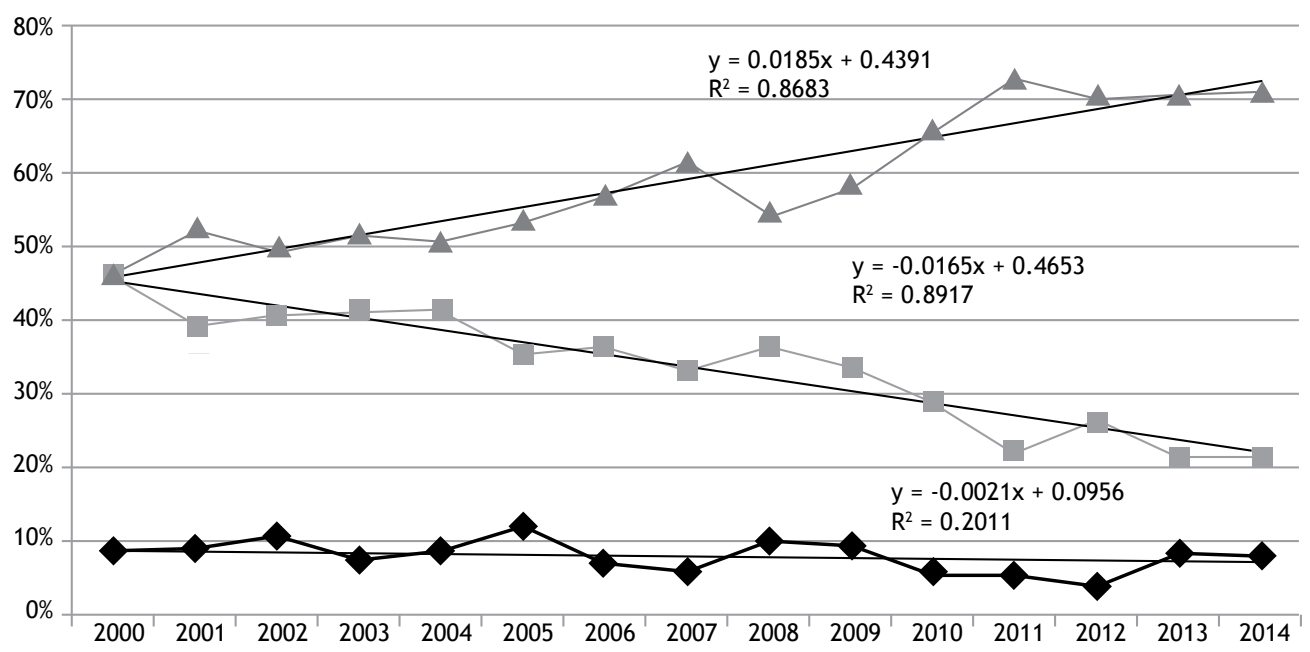

Figure 3. Distribution of all early-stage, locally advanced (LA), and advanced/metastatic (AM) lung cancer cases, by histology and year of diagnosis, Brazil. In A, adenocarcinoma. In B, squamous cell carcinoma. In $C$, small cell carcinoma. 
treated at a cancer institute in Brazil and found that, in almost $80 \%$ of the first treatments, the diagnosis of LC was not considered and that only $6.8 \%$ of the patients were diagnosed with the disease less than 30 days after symptom onset. Those authors also reported that, in only $18.5 \%$ of the cases, the delayed diagnosis of LC was due to the patient; therefore, in Brazil, the physician/health care system is largely responsible for the delay in diagnosis in patients with LC. ${ }^{(32)}$

In the present study, $10 \%$ to $18 \%$ of all patients with LC did not receive any cancer treatment, regardless of disease stage. This is probably due to the poor clinical status of patients making them unable to bear the risks of treatment, ${ }^{(33)}$ to patient personal preference not to be treated, or to delayed diagnosis. ${ }^{(32)}$ More than $75 \%$ of patients depend exclusively on the Brazilian Unified Health Care System, which, despite being purposed for providing universal care, has numerous problems related to access, ${ }^{(34)}$ delay in histological(32) or molecular ${ }^{(35)}$ diagnosis, treatment availability, and the wide disparity among cancer care centers in terms of the technology available for diagnosis or treatment. ${ }^{(36)}$ This situation in Brazil is similar to that in other Latin American countries, where the provision of care to patients with cancer is also precarious. ${ }^{(37)}$

Age is an independent risk factor for the development of cancer. ${ }^{(38)}$ In the present study, we found that the mean age of the diagnosed patients is increasing, which characterizes an increasingly older population. In addition, almost $35 \%$ of patients with early-stage disease, who have the best cure rates, are over 70 years of age. However, this population is often undertreated from an oncologic standpoint, ${ }^{(8,37)}$ although it may have good results. ${ }^{(39-41)}$ It can be speculated that, because of their comorbidities, elderly patients seek health care services earlier ${ }^{(29)}$ and can thus be diagnosed at earlier stages of the disease.

Overall, chemotherapy was the main treatment modality in the present study. It is the modality of choice for the systemic treatment of cancer. ${ }^{(33)}$ Radiotherapy and surgery are regional treatment modalities. The latter is the mainstay of the treatment for patients with early stage $\mathrm{LC}$, being used alone or in combination with chemotherapy in order to achieve better survival results. ${ }^{(42)}$ Surgery was performed at some point in only $15 \%$ of the cases, but it was the main treatment modality at early stages.

The present study has some limitations, especially because we analyzed retrospective data obtained from RHC. It has problems regarding the level of completeness of the variables analyzed, as well as lacking data on molecular analysis, comorbidities, and objective assessment of patient functional performance. Finally, histological confirmation of cases was not possible, nor was review of stage data. However, the study was based on data from large nationwide databases that have a significant body of information about the epidemiological profile with an emphasis on disease staging and treatment patterns of patients with $L C$ in Brazil, which were the object of this study.

To date, this has been the largest study analyzing TNM staging and treatment patterns of patients with LC in Brazil. The information gathered here may be valuable for understanding the current status of LC in Brazil and, consequently, for planning and implementing public health policies targeting LC patients in the country, such as combining screening programs with smoking cessation programs, training primary and secondary health care professionals to identify populations at increased risk, and identifying radiological lesions suspected of progressing to LC so that patients can be referred earlier to specialized health care facilities for diagnosis and treatment.

The present study showed that the frequency of stage III LC decreased significantly, a decrease characterized in part by a reduction in the frequency of the squamous cell carcinoma histological subtype, whereas the frequency of stage IV LC increased significantly and that of early-stage LC remained stable. In addition, our study showed that cancer treatment patterns, by clinical and/or pathological stage in patients with LC in Brazil, were in accordance with international guidelines.

\section{REFERENCES}

1. Siegel RL, Miller KD, Jemal A. Cancer statistics, 2018. CA Cancer J Clin. 2018;67(1):7-30. https://doi.org/10.3322/caac.21387

2. Brasil. Ministério da Saúde. Instituto Nacional de Câncer. Incidência de câncer no Brasil. Rio de Janeiro: INCA; 2018.

3. Silvestri GA, Gonzalez AV, Jantz MA, Margolis ML, Gould MK, Tanoue LT, et al. Methods for staging non-small cell lung cancer: Diagnosis and management of lung cancer, 3rd ed: American College of Chest Physicians evidence-based clinical practice guidelines. Chest. 2013;143(5 Suppl):e211S-e250S. https://doi.org/10.1378/ chest.12-2355

4. Rami-Porta R, Asamura H, Travis WD, Rusch WW. Lung cancer major changes in the American Joint Committee on Cancer eighth edition cancer staging manual. CA Cancer J Clin. 2017;67(2):138-155. https://doi.org/10.3322/caac.21390

5. Araujo LH, Baldotto C, Castro G Jr, Katz A, Ferreira CG, Mathias C, et al. Lung cancer in Brazil. J Bras Pneumol. 2018;44(1):55-64. https:// doi.org/10.1590/s1806-37562017000000135

6. McGuire A, Martin M, Lenz C, Sollano JA. Treatment cost of nonsmall cell lung cancer in three European countries: comparisons across France, Germany, and England using administrative databases. 2015;18(7):525-32. https://doi.org/10.3111/13696998.20 15.1032974

7. Costa G, Thuler LC, Ferreira CG. Epidemiological changes in the histological subtypes of 35,018 non-small-cell lung cancer cases in Brazil. Lung Cancer. 2016;97:66-72. https://doi.org/10.1016/j. lungcan.2016.04.019

8. Costa GJ, de Mello MJG, Ferreira CG, Thuler LCS. Undertreatment trend in elderly lung cancer patients in Brazil. J Cancer Res Clin Oncol. 2017;143(8):1469-1475. https://doi.org/10.1007/s00432-017-2412-8

9. Meza R, Meernik C, Jeon J, Cote ML. Lung cancer incidence trends by gender, race and histology in the United States, 1973-2010. PLoS One. 2015;10(3):e0121323. https://doi.org/10.1371/journal. pone. 0121323

10. Goldstraw P, Chansky K, Crowley J, Rami-Porta R, Asamura $H$, Eberhardt WE, et al. The IASLC Lung Cancer Staging Project: Proposals for Revision of the TNM Stage Groupings in the Forthcoming (Eighth) Edition of the TNM Classification for Lung Cancer. J Thorac Oncol. 2016;11(1):39-51. https://doi.org/10.1016/j.jtho.2015.09.009 
11. Lim C, Sekhon HS, Cutz JC, Hwang DM, Kamel-Reid S, Carter RF et al. Improving molecular testing and personalized medicine in nonsmall-cell lung cancer in Ontario. Curr Oncol. 2017;24(2):103-110. https://doi.org/10.3747/co.24.3495

12. Pirker R, Filipits M. Personalized treatment of advanced non-smallcell lung cancer in routine clinical practice. Cancer Metastasis Rev. 2016:35(1):141-50. https://doi.org/10.1007/s10555-016-9612-6

13. Brasil. Ministério da Saúde. Classificação de Tumores Malignos. Brasília: Ministério da Saúde; 2004

14. Organização Mundial da Saúde. CID-O: Classificação Internacional de Doenças Para Oncologia. 3rd edition. São Paulo: EDUSP; 2005

15. Edge SB, Compton CC. The American Joint Committee on Cancer: the 7th edition of the AJCC cancer staging manual and the future of TNM. Ann Surg Oncol. 2010;17(6):1471-4. https://doi.org/10.1245/ s10434-010-0985-4

16. Travis WD, Brambilla E, Nicholson AG, Yatabe Y, Austin JHM, Beasley MB, et al. The 2015 World Health Organization Classification of Lung Tumors: Impact of Genetic, Clinical and Radiologic Advances Since the 2004 Classification. J Thorac Oncol. 2015;10(9):1243-1260. https://doi.org/10.1097/JTO.0000000000000630

17. Alberg AJ, Brock MV, Ford JG, Samet JM, Spivack SD. Epidemiology of lung cancer: Diagnosis and management of lung cancer, 3rd ed: American College of Chest Physicians evidence-based clinical practice guidelines. Chest. 2013;143(5 Suppl):e1S-e29S. https://doi. org/10.1378/chest.12-2345

18. Lewis DR, Check DP, Caporaso NE, Travis WD, Devesa SS. US lung cancer trends by histologic type. Cancer. 2014;120(18):2883-92 https://doi.org/10.1002/cncr.28749

19. Lortet-Tieulent J, Soerjomataram I, Ferlay J, Rutherford $M$ Weiderpass E, Bray F. International trends in lung cancer incidence by histological subtype: adenocarcinoma stabilizing in men but still increasing in women. Lung Cancer. 2014;84(1):13-22. https://doi. org/10.1016/j.lungcan.2014.01.009

20. Lortet-Tieulent J, Renteria E, Sharp L, Weiderpass E, Comber H, Baas $P$, et al. Convergence of decreasing male and increasing female incidence rates in major tobacco-related cancers in Europe in 19882010. Eur J Cancer. 2015;51(9):1144-63. https://doi.org/10.1016/ ejca.2013.10.014

21. National Cancer Institute. Surveillance, Epidemiology, and End Results Program (SEER) [homepage on the Internet]. Bethesda: National Cancer Institute; [cited 2015 Oct 1]. Cancer Stat Facts: Lung and Bronchus Cancer. Available from: http://seer.cancer.gov/ statfacts/html/ lungb.html

22. Cancer Research UK [homepage on the Internet]. London: Cancer Research UK; [cited 2015 Oct 1]. Lung Cancer Statistics. Available

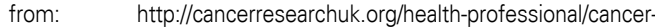
statistics/statistics-by-cancer-type/lung-cancer

23. Brasil. Ministério da Saúde. Instituto Nacional de Câncer (INCA) [homepage on the Internet]. Rio de Janeiro: INCA. [cited 2015 Oct 1]. Estimativa 2014: Incidência de câncer no Brasil. Available from: http://www2.inca.gov.br/wps/wcm/connect/inca/portal

24. Hochhegger B, Rafael G, Alves T, Irion KL, Fritscher CC, Fritscher LG. PET/CT imaging in lung cancer: indications and findings. $J$ Bras Pneumol. 2015;41(3):264-74. https://doi.org/10.1590/S180637132015000004479

25. National Lung Screening Trial Research Team, Aberle DR, Adams AM, Berg CD, Black WC, Clapp JD, et al. Reduced lung-cance mortality with low-dose computed tomographic screening. N Engl J Med. 2011;365(5):395-409. https://doi.org/10.1056/NEJMoa1102873

26. dos Santos RS, Franceschini JP, Chate RC, Ghefter MC, Kay F, Trajano AL, et al. Do Current Lung Cancer Screening Guidelines Apply for Populations With High Prevalence of Granulomatous Disease? Results from the First Brazilian Lung Cancer Screening Tria (BRELT1). Ann Thorac Surg. 2016;101(2):481-6; discussion 487-8. https://doi.org/10.1016/j.athoracsur.2015.07.013

27. Morgan L, Choi H, Reid M, Khawaja A, Mazzone PJ. Frequency of Incidental Findings and Subsequent Evaluation in Low-Dose
Computed Tomographic Scans for Lung Cancer Screening. Ann Am Thorac Soc. 2017;14(9):1450-1456. https://doi.org/10.1513/ AnnalsATS.201612-10230C

28. Brasil. Ministério da Saúde. Secretaria de Atenção à Saúde. Portaria no. 600, de 26 de junho de 2012. Aprova as Diretrizes Diagnósticas e Terapêuticas do Câncer de Pulmão. Brasília: o Ministério; 2012.

29. Silva ST, Martins MC, Faria FR, Cotta RM. Combating smoking in Brazil: the strategic importance of government actions [Article in Portuguese]. Cien Saude Colet. 2014;19(2):539-52. https://doi. org/10.1513/AnnalsATS.201612-10230C

30. Pinto M, Bardach A, Palacios A, Biz AN, Alcaraz A, Rodríguez B, et al. Carga de doença atribuível ao uso do tabaco no Brasil e potencial impacto do aumento de precos por meio de impostos [monograph on the Internet]. Buenos Aires: Instituto de Efectividad Clínica y Sanitaria 2017 [cited 2018 Jan 16]. Available from http://actbr.org.br/uploads/ arquivo/1173_Doc_Tec_Brasil_fi_al_plain_portugues_24-5-17.pdf

31. Tramontano AC, Sheehan DF, McMahon PM, Dowling EC, Holford TR, Ryczak K, et al. Evaluating the impacts of screening and smoking cessation programmes on lung cancer in a high-burden region of the USA: a simulation modelling study. BMJ Open. 2016;6(2):e010227. https://doi.org/10.1136/bmjopen-2015-010227

32. Lista M, Bes FC, Pereira JR, Ikari FK, Nikaedo SM. Excessiva demora no diagnóstico clínico do câncer de pulmão. Depende do médico, do paciente ou do sistema? Arq Med Hosp Fac Cienc Med St Casa São Paulo. 2008;53(1):6-9.

33. Novello S, Barlesi F, Califano R, Cufer T, Ekman S, Levra MG, et al. Metastatic non-small-cell lung cancer: ESMO Clinical Practice Guidelines for diagnosis, treatment and follow-up. Ann Oncol. 2016;27(suppl 5):v1-v27. https://doi.org/10.1093/annonc/mdw326

34. Grabois MF, Oliveira EX, Sá Carvalho M. Access to pediatric cancer care in Brazil: mapping origin-destination flows [Article in Portuguese]. Rev Saude Publica. 2013;47(2):368-78. https://doi. org/10.1590/S0034-8910.2013047004305

35. Ferreira CG. Lung cancer in developing countries: access to molecular testing. Am Soc Clin Oncol Educ B. 2013:327-331. https:// doi.org/10.1200/EdBook_AM.2013.33.327

36. de Sá VK, Coelho JC, Capelozzi VL, de Azevedo SJ. Lung cancer in Brazil: epidemiology and treatment challenges. Lung Cancer (Auckl). 2016;7:141-148. https://doi.org/10.2147/LCTT.S93604

37. Goss PE, Lee BL, Badovinac-Crnjevic T, Strasser-Weippl K, ChavarriGuerra Y, St Louis J, et al. Planning cancer control in Latin America and the Caribbean. Lancet Oncol. 2013;14(5):391-436. https://doi. org/10.1016/S1470-2045(13)70048-2

38. Smith BD, Smith GL, Hurria A, Hortobagyi GN, Buchholz TA. Future of cancer incidence in the United States: Burdens upon an aging changing nation. J Clin Oncol. 2009;27(17):2758-65. https://doi. org/10.1200/JCO.2008.20.8983

39. Pallis AG, Gridelli C, Wedding U, Faivre-Finn C, Veronesi G, Jaklitsch $\mathrm{M}$, et al. Management of elderly patients with NSCLC; updated expert's opinion paper: EORTC elderly task force, Lung Cancer Group and International Society for Geriatric Oncology. Ann Oncol. 2014;25(7):1270-83. https://doi.org/10.1093/annonc/mdu022

40. Costa GJ, Fernandes AL, Pereira JR, Curtis JR, Santoro IL. Survival rates and tolerability of platinum-based chemotherapy regimens for elderly patients with non-small-cell lung cancer (NSCLC). Lung Cancer 2006;53(2):171-6. https://doi.org/10.1016/j.lungcan.2006.04.006

41. Pallis AG, Gridelli C, van Meerbeeck JP, Greillier L, Wedding U, Lacombe D, et al. EORTC Elderly Task Force and Lung Cancer Group and International Society for Geriatric Oncology (SIOG) experts' opinion for the treatment of non-small-cell lung cancer in an elderly population. Ann Oncol. 2010;21(4):692-706. https://doi.org/10.1093/ annonc/mdp360

42. Postmus PE, Kerr KM, Oudkerk M, Senan S, Waller DA Vansteenkiste J, et al. Early and locally advanced non-small-cell lung cancer (NSCLC): ESMO Clinical Practice Guidelines for diagnosis, treatment and follow-up. Ann Oncol. 2017;28(suppl_4):iv1-iv21. https://doi.org/10.1093/annonc/mdx222 